OPEN ACCESS

Edited by:

Akio Adachi,

Kansai Medical University, Japan

Reviewed by:

Janine Kimpel,

Innsbruck Medical University, Austria

Steve Kwilas,

United States Army Medical Research Institute of Infectious Diseases

(USAMRIID), United States

Alexandra Tortorici,

University of Washington,

United States

*Correspondence:

Anwar M. Hashem

amhashem@kau.edu.sa

Specialty section:

This article was submitted to

Virology,

a section of the journal

Frontiers in Microbiology

Received: 04 June 2020

Accepted: 30 July 2020

Published: 04 September 2020

Citation:

Almahboub SA, Algaissi A, Alfaleh MA, ElAssouli M-Z and Hashem AM (2020) Evaluation of Neutralizing Antibodies Against Highly Pathogenic Coronaviruses:

A Detailed Protocol for a Rapid Evaluation of Neutralizing Antibodies Using Vesicular Stomatitis Virus

Pseudovirus-Based Assay.

Front. Microbiol. 11:2020.

doi: 10.3389/fmicb.2020.02020

\section{Evaluation of Neutralizing Antibodies Against Highly Pathogenic Coronaviruses: A Detailed Protocol for a Rapid Evaluation of Neutralizing Antibodies Using Vesicular Stomatitis Virus Pseudovirus-Based Assay}

\author{
Sarah A. Almahboub ${ }^{1}$, Abdullah Algaissi ${ }^{1,2,3}$, Mohamed A. Alfaleh ${ }^{1,4}$, M-Zaki ElAssouli ${ }^{1}$ \\ and Anwar M. Hashem ${ }^{1,5 *}$
}

1 Vaccines and Immunotherapy Unit, King Fahd Medical Research Center, King Abdulaziz University, Jeddah, Saudi Arabia, 2 Department of Medical Laboratories Technology, College of Applied Medical Sciences, Jazan University, Jazan, Saudi Arabia, ${ }^{3}$ Medical Research Center, Jazan University, Jazan, Saudi Arabia, ${ }^{4}$ Faculty of Pharmacy, King Abdulaziz University, Jeddah, Saudi Arabia, ${ }^{5}$ Department of Medical Microbiology and Parasitology, Faculty of Medicine, King Abdulaziz University, Jeddah, Saudi Arabia

Emerging highly pathogenic human coronaviruses (CoVs) represent a serious ongoing threat to the public health worldwide. The spike (S) proteins of CoVs are surface glycoproteins that facilitate viral entry into host cells via attachment to their respective cellular receptors. The $\mathrm{S}$ protein is believed to be a major immunogenic component of CoVs and a target for neutralizing antibodies (nAbs) and most candidate vaccines. Development of a safe and convenient assay is thus urgently needed to determine the prevalence of CoVs nAbs in the population, to study immune response in infected individuals, and to aid in vaccines and viral entry inhibitor evaluation. While live virus-based neutralization assays are used as gold standard serological methods to detect and measure nAbs, handling of highly pathogenic live CoVs requires strict biocontainment conditions in biosafety level-3 (BSL-3) laboratories. On the other hand, use of replication-incompetent pseudoviruses bearing CoVs $S$ proteins could represent a safe and useful method to detect nAbs in serum samples under biosafety level-2 (BSL2) conditions. Here, we describe a detailed protocol of a safe and convenient assay to generate vesicular stomatitis virus (VSV)-based pseudoviruses to evaluate and measure nAbs against highly pathogenic CoVs. The protocol covers methods to produce VSV pseudovirus bearing the S protein of the Middle East respiratory syndrome-CoV (MERS$\mathrm{CoV}$ ) and the severe acute respiratory syndrome-CoV-2 (SARS-CoV-2), pseudovirus titration, and pseudovirus neutralization assay. Such assay could be adapted by different laboratories and researchers working on highly pathogenic CoVs without the need to handle live viruses in the BSL-3 environment.

Keywords: coronaviruses, Middle East respiratory syndrome coronavirus, severe acute respiratory syndrome coronavirus 2 , serological assay, vesicular stomatitis virus pseudovirus 


\section{INTRODUCTION}

Coronaviruses (CoVs) are the largest group of enveloped positive-sense RNA viruses that primarily infect the respiratory and gastrointestinal tracts of birds and mammals (Fehr and Perlman, 2015). Many CoVs are zoonotic viruses that are capable of crossing the species barrier and infecting other hosts including humans (Kandeel et al., 2020). Human CoVs mainly cause mild respiratory tract infections, and no highly pathogenic CoVs were recognized until the beginning of the twenty-first century (Cui et al., 2019). Since 2002, a number of highly pathogenic human CoVs have emerged including the severe acute respiratory syndrome-CoV (SARS-CoV) in 2002/2003 and the Middle East respiratory syndrome-CoV (MERS-CoV) in 2012 (Ksiazek et al., 2003; Zaki et al., 2012). In December 2019, a novel human highly pathogenic CoV known as SARS-CoV-2 has emerged in Wuhan, China, causing the coronavirus disease 2019 (COVID-19) pandemic (Wu et al., 2020; Zhu et al., 2020). While SARS-CoV has disappeared, both MERS-CoV and SARS-CoV-2 continue to be a major global threat especially that to date no clinically proven treatments or vaccines are available for human use (Al-Amri et al., 2017; Liu et al., 2018; Ma et al., 2020; Padron-Regalado, 2020; Tse et al., 2020).

The spike (S) proteins of CoVs are surface glycoproteins that facilitate viral entry into host cells. The $\mathrm{S} 1$ subunit at the $\mathrm{N}$ terminal end of the $\mathrm{S}$ protein contains the receptorbinding domain (RBD) responsible for the attachment to cellular receptors, while the S2 subunit at the C-terminus mediates the fusion with the host membranes. The $\mathrm{S}$ protein of SARS$\mathrm{CoV}$ and SARS-CoV-2 binds to the angiotensin-converting enzyme 2 (ACE2) as a cellular receptor, while the $S$ protein of MERS-CoV utilizes the dipeptidyl peptidase 4 (DPP-4) (Liu et al., 2018; Hoffmann et al., 2020). The S protein, particularly the RBD, is considered as a major immunogenic component of CoVs and a target for most neutralizing antibodies (nAbs).

Although live virus-based neutralization methods are the gold standard serological assays to detect and measure nAbs levels, they require working under strict bio-containment conditions in biosafety level-3 (BSL-3) laboratories when working with highly pathogenic CoVs (Algaissi and Hashem, 2020). Other serological assays such as conventional enzymelinked immunosorbent assay (ELISA) and immunofluorescence assay (IFA) have been utilized for $\mathrm{CoV}$ antibody screening; however, cross-reactivity with other common CoVs may lead to false-positive results (Lester et al., 2019; Degnah et al., 2020). Additionally, positivity in these assays does not necessarily reflect the presence of nAbs in samples, requiring other confirmatory functional bioassays. Thus, replicationincompetent pseudotyped viruses bearing $S$ proteins from highly pathogenic CoVs could represent an alternative safe and convenient method for CoVs $\mathrm{nAb}$ detection and quantification in serum samples under biosafety level-2 (BSL-2) conditions (Almasaud et al., 2020). Several reports have shown encouraging results by utilizing vesicular stomatitis virus (VSV) as a platform to generate pseudoviruses that can be used in seroepidemiological studies, vaccine development, monoclonal antibodies and entry inhibitors screening, and basic research investigations of CoVs (Fukushi et al., 2005; Lester et al., 2019; Nie et al., 2020).

VSV is a zoonotic enveloped negative-stranded RNA virus that infects a wide range of animals and less frequently humans causing mild flu-like illness symptoms (Rodriguez, 2002; Tani et al., 2011). The small genome (11 kb), simple structure, and ability to grow in different types of mammalian cells with high titer made VSV a promising virus vector and a valuable tool in molecular biology and virology fields (Ruedas and Connor, 2017). Interestingly, recombinant VSV (rVSV) with G gene being replaced by reporter luciferase gene (rVSV- $\Delta$ G-luciferase) can normally bud from cells transfected with mammalian expression plasmid encoding VSV G protein or heterologous surface protein from other viruses (Whitt, 2010; Tani et al., 2011). Thus, rVSV- $\Delta$ G-luciferase system could be used to produce singleround replication-incompetent VSV pseudoviruses bearing any viral surface glycoprotein especially from those requiring work under BSL-3 and BSL-4 containments in BSL-2 laboratories (Whitt, 2010).

In these detailed protocols, we explain step by step how to generate VSV pseudoviruses bearing $\mathrm{S}$ proteins from MERS-CoV and SARS-CoV-2 using transient expression in BHK-21/WI2 cells (Protocol 1). This is followed by pseudovirus titration method (Protocol 2) and pseudovirus-based neutralization assay (Protocol 3) relying on reading quantitative luciferase luminescence signals. We utilized this system to conduct seroprevalence studies and measure nAbs in MERS-CoV and SARS-CoV-2 infected patients. Notes and comments have been added to overcome any difficulties. We believe that the described platform (Figure 1) can be adapted and used for research studies as well as diagnostic purposes.

\section{MATERIALS AND METHODS}

The detailed protocols described here can serve as convenient methods to detect MERS-CoV and SARS-CoV-2 nAbs in serum samples under BSL- 2 conditions. The pseudovirus assays detailed here could also be used to evaluate the immunogenicity of vaccines and potency of monoclonal antibodies, other biologics, and small molecules. These assays rely on a well-established technique using rVSV- $\Delta \mathrm{G} / \mathrm{G}^{*}$-luciferase pseudovirus system. Most reagents required for this system are commercially available and could be adopted and used by researchers and laboratories around the world. Such assays provide a number of advantages over standard serological assays including ability to evaluate nAbs in serum samples under BSL-2 conditions with minimal equipment and relatively low cost.

\section{Materials and Equipment}

- Baby Hamster kidney BHK-21/WI-2 cell line (Kerafast catalog \# EH1011).

- African Green monkey kidney-derived Vero E6 cell line [American Type Culture Collection (ATCC) catalog \# 1586; Huh-7 cells could be used instead of Vero E6 cells]. 
- Dulbecco's modified Eagle's medium with L-glutamine (DMEM; BioWhittaker catalog \#12-604F) supplemented with $5 \%$ fetal bovine serum (i.e., DMEM-5).

- Opti-MEM ${ }^{\circledR}$ I $\left(\begin{array}{ll}1 & \times\end{array}\right)$ reduced-serum medium (Gibco catalog \# 31985062 or equivalent).

- $1 \times$ phosphate-buffered saline (PBS) (Biosera catalog \# LM-S2041 or equivalent).

- $1 \times$ trypsin (Gibco catalog \# 12484-028 or equivalent).

- pcDNA-S: Mammalian expression vector expressing MERS-CoV or SARS-CoV-2 S protein.

- pCAGGS-G-Kan plasmid (Kerafast catalog \# EH1017).

- Lipofectamine ${ }^{\mathrm{TM}} 2000$ transfection reagent (Invitrogen catalog \# 11668019; other transfection reagents or methods could be used as alternatives if available).

- rVSV- $\Delta$ G/G*-luciferase (Kerafast catalog \# EH1020-PM).

- Rabbit anti-VSV-G polyclonal antibodies (commercial or in-house made; other species could be used to generate antibodies).

- $5 \times$ cell culture lysis reagent (CCLR) (Promega catalog \# E1531).

- Luciferase assay system (Promega catalog \# E1501).

- Serum samples.

- 96-well cell culture plate (white or black plate with clear bottom, COSTAR or equivalent).

- U-shaped 96-well cell culture plate (SPL Life Sciences catalog \# 30096 or equivalent).

- Sterile reservoirs.

- Tissue culture T175 flasks with vented caps (SPL Life Sciences catalog \# 71175 or equivalent).

- Sterile microcentrifuge tubes.

- Polypropylene sterile conical tubes:

$15 \mathrm{ml}$ (Falcon catalog \# 352099 or equivalent). $50 \mathrm{ml}$ (Falcon catalog \# 352098 or equivalent).

- Sterile serological pipettes.

$5 \mathrm{ml}$ (SPL Life Sciences \# 91005 or equivalent).

$10 \mathrm{ml}$ (SPL Life Sciences \# 91010 or equivalent).

$25 \mathrm{ml}$ (SPL Life Sciences \# 91025 or equivalent).

- Micropipettes.

- Micropipette tips.

$10-\mu l$ filter tips, low retention (BIOLOGIX catalog \# 230011 or equivalent).

$200-\mu 1$ filter tips, low retention (BIOLOGIX catalog \# 23-0201 or equivalent).

$1,000-\mu$ f filter tips, low retention (BIOLOGIX catalog \# 23-1001 or equivalent).

- BSL-2 cabinet.

- Cell counter hemocytometer or equivalent.

- $37^{\circ} \mathrm{C}$ incubator with $\mathrm{CO}_{2}$ (Heal Force HF90 or equivalent).

- Water bath (Lab Tech LWB-111D or equivalent).

- Benchtop low-speed centrifuge (Sigma 2-16P or equivalent).

- Inverted microscope (Olympus CK30 or equivalent).

- Timer.
- Ultra-low freezer $\left(-80^{\circ} \mathrm{C}\right)$.

- $70 \%$ ethanol; to sanitize all materials before use it inside the BSL-2 cabinet.

\section{Methods}

\section{Protocol 1: Production of Vesicular Stomatitis Virus Pseudoviruses Bearing Coronavirus S Protein}

This protocol can be used to generate VSV pseudoviruses bearing $S$ protein (rVSV- $\triangle \mathrm{G} / \mathrm{S}^{*}$-luciferase) from either MERS$\mathrm{CoV}$ or SARS-CoV-2 in BHK-21/WI-2 cell line (Figure 1A). Full-length codon-optimized MERS-CoV (GenBank accession number: KF958702) or SARS-CoV-2 (GenBank accession number: MN908947) S genes were synthesized and cloned into pcDNA3.1 mammalian expression vector. Genes were cloned into the vector following standard cloning techniques. Plasmids were transformed into $\mathrm{DH} 5 \alpha$ cells or similar cells using ampicillin as a selection marker. High-quality purified plasmids were obtained using commercially available endotoxinfree maxiprep kit. A pCAGGS expression plasmid encoding VSV glycoprotein (pCAGGS-G) was used to generate rVSV$\triangle \mathrm{G} / \mathrm{G}^{*}$ luciferase, which was used as a positive control (PC) pseudovirus. Lipofectamine ${ }^{\mathrm{TM}} 2000$ transfection reagent was used to deliver the constructed plasmids into BHK21/WI-2 cells to express the desired protein on the cells surface. In total, 3 days is needed to generate rVSV- $\Delta \mathrm{G} / \mathrm{S}^{*}$ luciferase pseudovirus by using BHK-21/WI-2 cells at $\sim 70 \%$ confluency in a T175 tissue culture flask as described in the following steps.

\section{Day 1: BHK-21/WI-2 Cell Preparation}

1. In BSL-2 cabinet, passage T75 tissue culture flask of $90 \%$ confluent BHK-21/WI-2 cells at $1: 4$ ratio $\left(\sim 3 \times 10^{6}\right.$ cells $)$ into a T175 tissue culture flask using DMEM-5 to be $\sim 70 \%$ confluent the next day.

2. Incubate the cells overnight at $37^{\circ} \mathrm{C}$ in $5 \% \quad \mathrm{CO}_{2}$ humidified incubator.

Day 2: BHK-21/WI-2 Cell Transfection With Expression Vector Encoding Coronavirus S Protein

1. The next day, check the cells under the inverted microscope to ensure that they are healthy and at the required confluency.

2. Replace the growth medium of the plated BHK-21/WI-2 cells in the T175 tissue culture flask with $22 \mathrm{ml}$ of prewarmed DMEM-5. Return the flask to the incubator until the transfection mixture is prepared.

3. Add $1.75 \mathrm{ml}$ of Opti-MEM reduced serum medium into two 15-ml sterile polypropylene conical tubes: tube A receives $46 \mu \mathrm{g}$ of a mammalian expression vector expressing $S$ protein from either MERS-CoV or SARSCoV-2, while tube $\mathrm{B}$ receives $92 \mu \mathrm{l}$ of Lipofectamine ${ }^{\mathrm{TM}}$ 2000 transfection reagent. As a PC, a T175 flask of BHK-21/WI-2 cells can be transfected with expression plasmid encoding VSV-G (pCAGGS-G-Kan plasmid) to generate $\operatorname{rVSV}-\Delta \mathrm{G} / \mathrm{G}^{*}$ luciferase (this stock can be used 
A. Generation

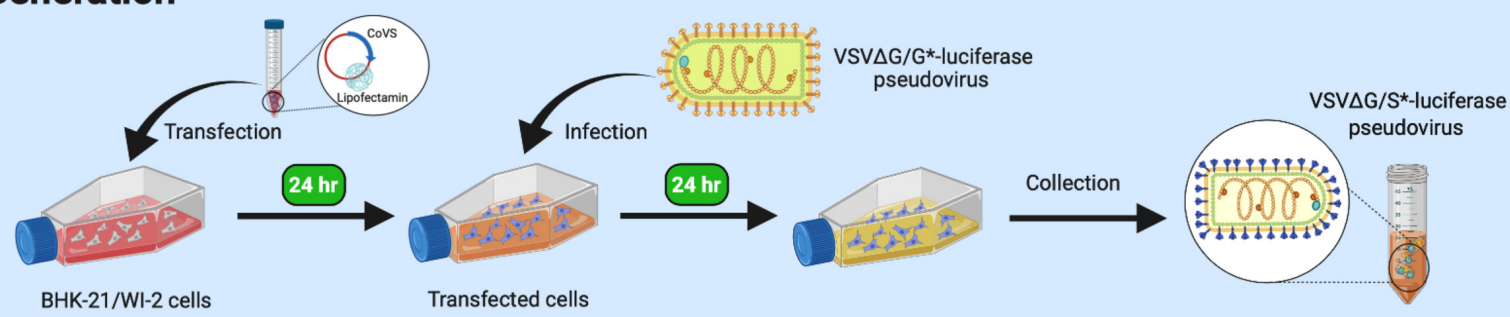

\section{B. Titration}
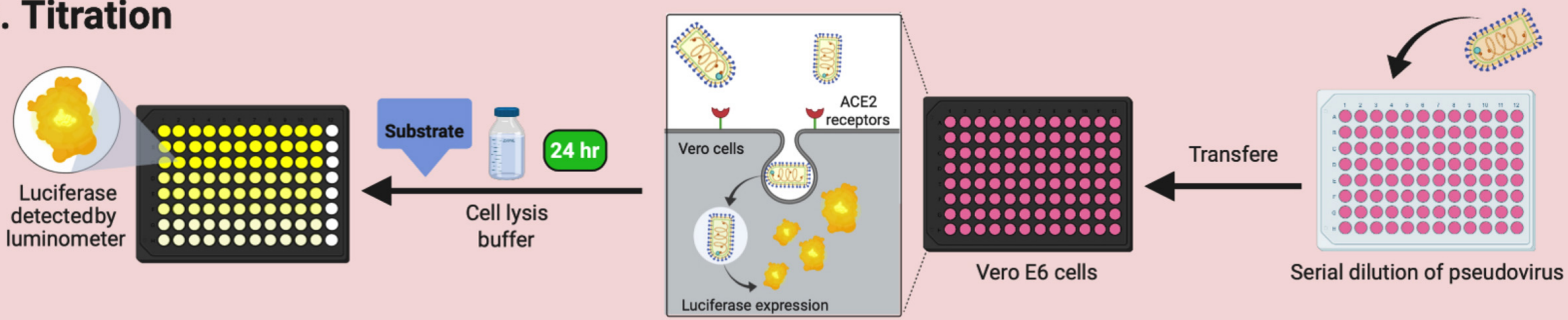

\section{Neutralization}
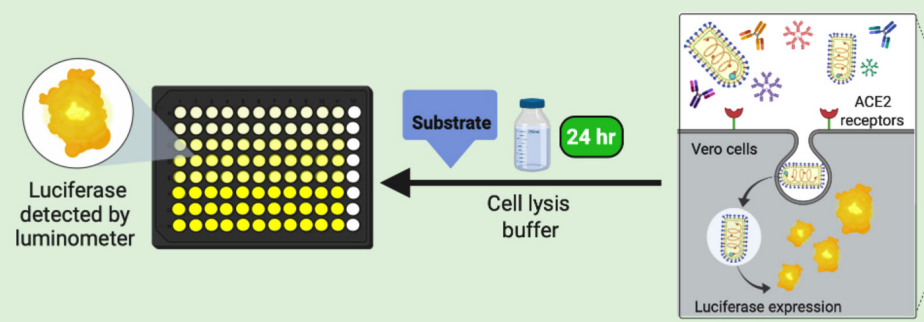

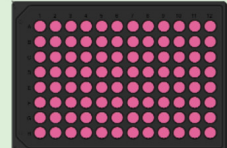

Vero E6 cells

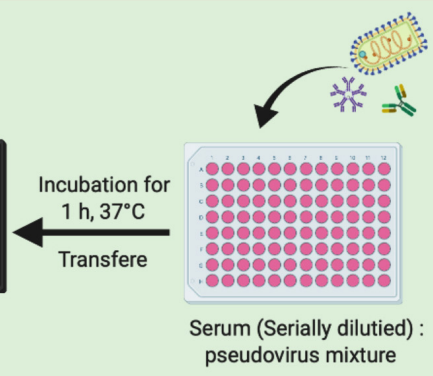

FIGURE 1 | Graphical overview of Protocols 1, 2, and 3. (A) Protocol 1: generation of VSV pseudoviruses bearing CoV S protein. (B) Protocol 2: titration assay of the generated VSV pseudoviruses. (C) Protocol 3: neutralization assay to determine CoV-specific nAb titers in serum samples. VSV, vesicular stomatitis virus; CoV, coronavirus; nAb, neutralizing antibody.

later as a $\mathrm{PC}$ in the titration assay or to replenish rVSV$\Delta \mathrm{G} / \mathrm{G}^{*}$ luciferase stock).

4. Mix the mixture in each tube by pipetting up and down 10 times, and incubate them for $5 \mathrm{~min}$ at room temperature.

5. Transfer the plasmid mixture in tube A into tube B and mix gently by pipetting up and down 10 times.

6. Incubate the transfection mixture for $20 \mathrm{~min}$ at room temperature.

7. Take out the BHK-21/WI-2 cells in the T175 flask from the incubator and transfect the cells by adding the $3.5 \mathrm{ml}$ transfection mixture dropwise on the cell monolayer using 5-ml sterile serological pipette while swirling the flask gently to ensure even dispersal.

8. Incubate the transfected tissue culture flask for $24 \mathrm{~h}$ at $37^{\circ} \mathrm{C}$ in $5 \% \mathrm{CO}_{2}$ humidified incubator.

\section{Day 3: Infection of Transfected Cells With} $r V S V-\Delta G / G^{*}$-Luciferase

1. In a 15-ml polypropylene sterile tube, prepare the virus inoculation mixture by adding $5 \mathrm{ml}$ of DMEM5 containing an amount of $\mathrm{rVSV}-\Delta \mathrm{G} / \mathrm{G}^{*}$ luciferase equivalent to multiplicity of infection (MOI) of
4 using the working stock virus from Kerafast or in-house produced $\mathrm{rVSV}-\Delta \mathrm{G} / \mathrm{G}^{*}$ luciferase (see Generation of $r V S V-\triangle G / M E R S-S^{*}$-Luciferase and $r V S V-\triangle G / S A R S-2-S^{*}$-Luciferase Pseudoviruses for $\mathrm{rVSV}-\Delta \mathrm{G} / \mathrm{G}^{*}$ luciferase titration).

2. Take out the T175 flask containing the transfected BHK21/WI-2 cells from Day 2 experiment from the incubator, and remove the growth medium.

3. Infect the cells with the $5 \mathrm{ml}$ of media containing the rVSV$\Delta \mathrm{G} / \mathrm{G}^{*}$ luciferase, and make sure to distribute equally over the cell monolayer.

4. Incubate the cells for $1 \mathrm{~h}$ at $37^{\circ} \mathrm{C}$ in $5 \% \mathrm{CO}_{2}$ humidified incubator, and distribute the virus by gently rocking the T175 flask every $10 \mathrm{~min}$.

5. During the incubation time, dilute rabbit polyclonal anti-VSV-G antibodies at a 1:1,000 dilution in a 50-ml polypropylene sterile conical tube containing $15 \mathrm{ml}$ of pre-warmed DMEM-5. Alternatively, $1 \mu \mathrm{g} / \mathrm{ml}$ of anti-VSV-G antibody (Kerafast Cat \# EB0010) can be used.

6. After 1-h incubation, remove the virus inoculum and wash the cells twice with $12 \mathrm{ml}$ of pre-warmed $1 \times$ PBS. 
7. Add the prepared $15 \mathrm{ml}$ of DMEM-5 supplemented with anti-VSV-G antibodies to the cell monolayer. In case of generating rVSV- $\Delta \mathrm{G} / \mathrm{G}^{*}$-luciferase stock, use DMEM-5 without anti-VSV-G antibodies.

8. Incubate the flask for $24 \mathrm{~h}$ at $37^{\circ} \mathrm{C}$ in $5 \% \quad \mathrm{CO}_{2}$ humidified incubator.

Day 4: Collection and Storage of the Generated Vesicular Stomatitis Virus Pseudoviruses

1. The next day, collect the supernatant that contains the VSV pseudoviruses in a 50-ml polypropylene sterile conical tube.

2. Remove the cells debris by centrifugation of the supernatant at $600 \times \mathrm{g}$ for $5 \mathrm{~min}$.

3. Aliquot the clarified supernatant as $1 \mathrm{ml}$ into appropriately labeled sterile microcentrifuge tubes.

4. Store the generated pseudoviruses stocks at $-80^{\circ} \mathrm{C}$.

\section{Protocol 2: Titration Assay of the Generated Vesicular Stomatitis Virus Pseudoviruses by Measuring Luciferase Activity}

This protocol is based on the use of luciferase activity as a main readout of the system to titrate the produced rVSV pseudoviruses (Figure 1B). The measured luciferase activity is defined as relative luminescence unit (RLU). This protocol is summarized in Figure 2. The protocol details are in the following steps.

\section{Day 1: Cell Preparation}

1. Count Vero E6 cells from confluent T75 tissue culture flask using a hemocytometer slide and trypan blue solution. It is preferred to subculture confluent Vero E6 at 1:4 ratio $48 \mathrm{~h}$ before use.

2. Prepare $11 \mathrm{ml}$ of Vero E6 cells suspension at a density of $2 \times 10^{5}$ cells $/ \mathrm{ml}$ in a $50-\mathrm{ml}$ polypropylene sterile conical tube using pre-warmed DMEM-5.
3. Seed the Vero E6 cells suspension in a 96-well white or black cell culture plate with clear bottom by distributing $100 \mu \mathrm{l}$ of the cells/well using multichannel pipette, sterile filtered tips, and sterile reservoir. Every $100 \mu \mathrm{l}$ should contain $2 \times 10^{4}$ cells in total.

4. Incubate the seeded 96 -well plate for $24 \mathrm{~h}$ at $37^{\circ} \mathrm{C}$ in $5 \%$ $\mathrm{CO}_{2}$ humidified incubator.

To save time, steps 1-4 can be done on Day 3 or 4 of Protocol 1.

Day 2: Cell Infection With Generated Vesicular Stomatitis Virus Pseudoviruses Bearing Coronavirus S Gene

1. In a sterile U-shaped 96-well cell culture plate, add $60 \mu \mathrm{l}$ of pre-warmed DMEM-5 to all wells in column 12 as a negative cell control; cell-only control (CC).

2. Add $60 \mu \mathrm{l}$ of pre-warmed DMEM-5 to all wells in columns 1-11 in rows $\mathrm{B}$ to $\mathrm{H}$ using multichannel pipette, filtered tips, and sterile reservoir.

3. Thaw the supernatant containing generated VSV pseudotyped virus on ice.

4. Add $120 \mu \mathrm{l}$ of the supernatant containing rVSV- $\Delta \mathrm{G} / \mathrm{S}^{*}$ luciferase pseudovirus in wells A1 to A8. As an example, rVSV- $\Delta$ G/MERS-S*-luciferase pseudovirus can be added in wells A1 to A4 and rVSV- $\Delta$ G/SARS-2-S*-luciferase pseudovirus in wells A5 to A8.

5. As a PC, add $120 \mu \mathrm{l}$ of the supernatant containing rVSV$\Delta \mathrm{G} / \mathrm{G}^{*}$-luciferase pseudovirus in wells A9 to A11.

6. Remove $60 \mu \mathrm{l}$ from virus-containing wells in row A (A1A11), and perform 1:2 serial dilution downward to all wells below using multichannel pipette and filtered tips. Other dilutions such as 1:3 or 0.5 log could be used.

7. During each dilution step, mix well by pipetting eight times up and down.

8. Continue the dilution until row $\mathrm{H}$, and discard the final 60 $\mu \mathrm{l}$ from the last wells in row $\mathrm{H}$.

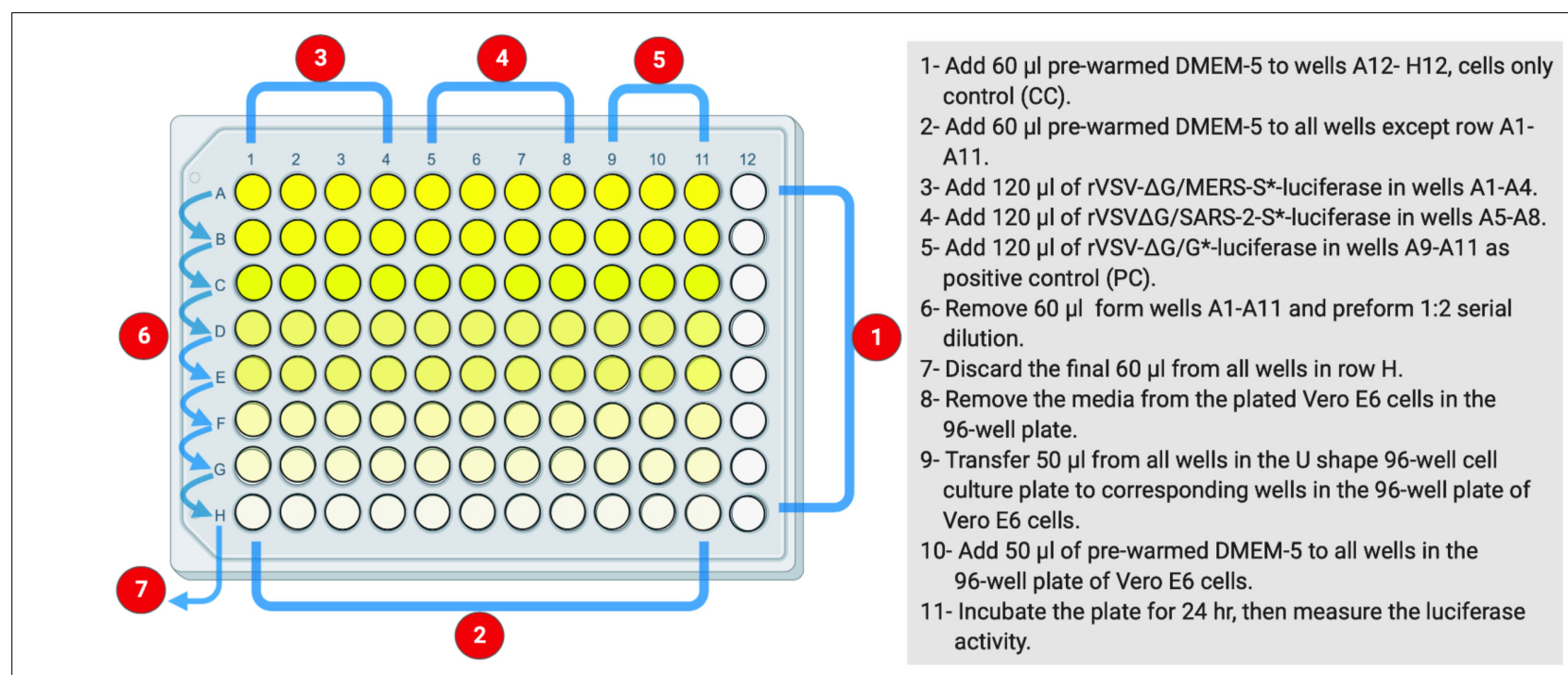

FIGURE 2 | The layout of U-shaped 96-well cell culture plat for $r V S V-\Delta G / S^{*}$-luciferase pseudovirus titration in Protocol 2. The preparation steps are indicated in sequential numbers. rVSV, recombinant vesicular stomatitis virus. 
9. Remove the media from the plated Vero E6 cells in the 96well plate that was seeded on Day 1.

10. With the use of multichannel pipette and filtered tips, transfer $50 \mu \mathrm{l}$ from all wells in the U-shaped 96-well cell culture plate to corresponding wells in the 96-well plate of Vero E6 cells.

11. Add $50 \mu \mathrm{l}$ of pre-warmed DMEM-5 to all wells in the 96well plate of Vero E6 cells.

12. Incubate the plate for $24 \mathrm{~h}$ at $37^{\circ} \mathrm{C}$ in $5 \% \mathrm{CO}_{2}$ humidified incubator.

\section{Day 3: Luciferase Assay}

1. Prepare $1 \times$ lysis buffer from $5 \times$ CCLR in a $15-\mathrm{ml}$ polypropylene sterile conical tube by adding four volumes of water to 1 volume of $5 \times$ CCLR. A total of $2.5 \mathrm{ml}$ of $1 \times$ lysis buffer will be enough for each 96-well plate (20 $\mu \mathrm{l} /$ well).

2. By using Promega luciferase assay system (Promega catalog \# E1501), prepare the luciferase assay reagent by adding $10 \mathrm{ml}$ of luciferase assay buffer to a vial containing lyophilized luciferase assay substrate.

3. Remove the growth media from all wells in the 96-well cell culture plate of Vero E6 cells from Day 2.

4. Rinse the cells in all wells with $50 \mu l 1 \times$ PBS, and make sure not to dislodge the cells. Ensure complete removal of any residual liquid.

5. Add $20 \mu \mathrm{l}$ of the prepared $1 \times$ cells lysis buffer to each well.

6. Add $50 \mu \mathrm{l}$ of the prepared luciferase reagent to each well. Work with two columns each time to complete steps 5-7, which include cell lysis and addition of luciferase reagent, and measure the luciferase activity.
Repeat cycle for the remaining columns. Alternatively, a luminometer supplied with two injectors for both lysis buffer and luciferase substrate can be used to facilitate the process by measuring light produced from the reaction $\sim 8 \mathrm{~s}$ after adding the substrate using an integration time of 5-30 s.

7. Measure the light produced for a period of $\sim 8 \mathrm{~s}$ using luminometer, and save the results. The reaction is nearly constant for about $1 \mathrm{~min}$ and then decays slowly, with a half-life of $\sim 10 \mathrm{~min}$. The typical delay time is $2 \mathrm{~s}$, and the typical read time is $10 \mathrm{~s}$.

8. Plot virus dilution vs. RLU readout to select the needed amount of virus for neutralization assay. Select a dilution that results in a signal above cell-only control and in the linear part of the curve.

\section{Protocol 3: Neutralization Assay to Determine Coronavirus-Specific Neutralizing Antibody Titers in Serum Samples}

As in Protocol 2, measuring of $\mathrm{nAb}$ titers depends on using luciferase-based assay. Inhibition of the generated pseudovirus entry into Vero E6 cells by nAbs is correlated with the decreased levels of luciferase expression signals. This assay could be used to measure nAb titers from different species including humans and animals as well as testing monoclonal antibodies. Figure 3 illustrates the workflow as it is described in the following steps.

\section{Day 1: Cell Preparation}

1. Seed $2 \times 10^{4}$ Vero E6 cells per well in a 96-well white or black cell culture plate with clear bottom. This can be achieved by following steps $1-4$ on Day 1 in

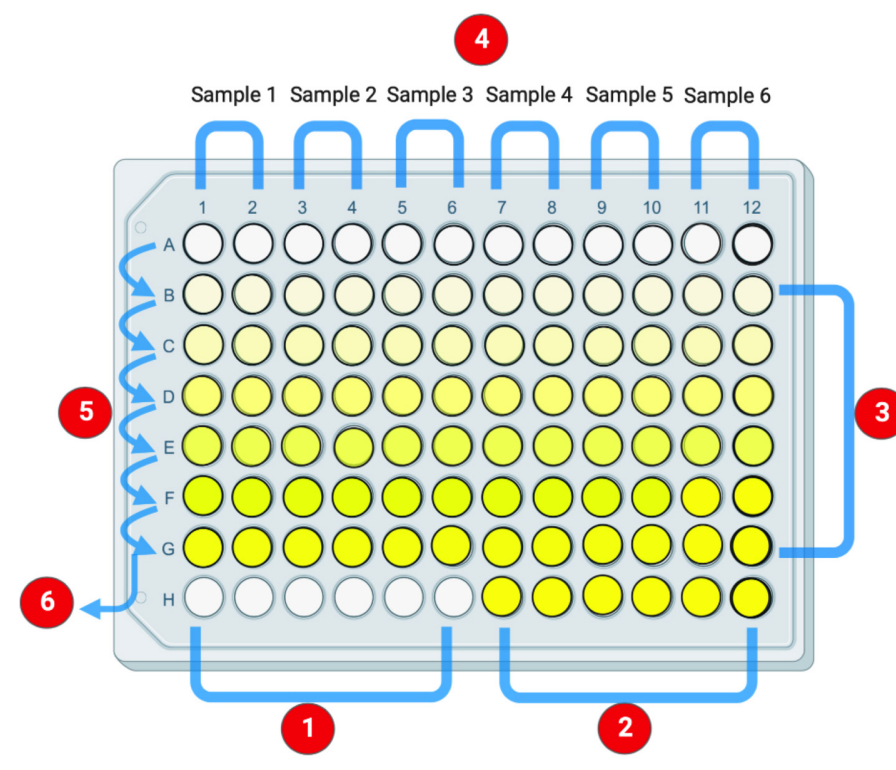

1- Add $120 \mu$ pre-warmed DMEM-5 to in wells in $\mathrm{H} 1-\mathrm{H} 6$, cell only control (CC).

2- Add $60 \mu$ pre-warmed DMEM-5 to in wells in $\mathrm{H} 7-12$, virus control (VC).

3- Add $60 \mu \mathrm{l}$ pre-warmed DMEM- 5 to all wells in columns $1-12$ in rows B-G.

4- Add $120 \mu$ l of $1: 10$ diluted serum samples in wells A1-A12, each sample in duplicate.

5- Remove $60 \mu$ form wells A1-A12 and preform 1:2 serial dilution.

6- Discard the final $60 \mu \mathrm{l}$ from all wells in row $\mathrm{G}$.

7- Add $60 \mu$ lof pseudovirus (rVSV- $\triangle \mathrm{G} /$ MERS-S*-luciferase or rVSV- $\Delta \mathrm{G} / \mathrm{SARS}-2-\mathrm{S}^{*}$-luciferase to all wells expect wells $\mathrm{H} 1-\mathrm{H} 6$.

8- Incubate the 96 -well plate for $1 \mathrm{hr}$ at $37^{\circ} \mathrm{C}$ in $5 \% \mathrm{CO}_{2}$ incubator.

9- Transfer $100 \mu$ from all wells in the $U$ shape 96 -well cell culture plate to corresponding wells in 96-well plate of Vero E6 cells.

10- Incubate the plate for $24 \mathrm{hr}$, then measure the luciferase activity.

FIGURE 3 | The layout of U-shaped 96-well cell culture plat for $r V S V-\Delta G / S^{*}$-luciferase pseudovirus neutralization assay in Protocol 3. The preparation steps are indicated in sequential numbers. rVSV, recombinant vesicular stomatitis virus. 

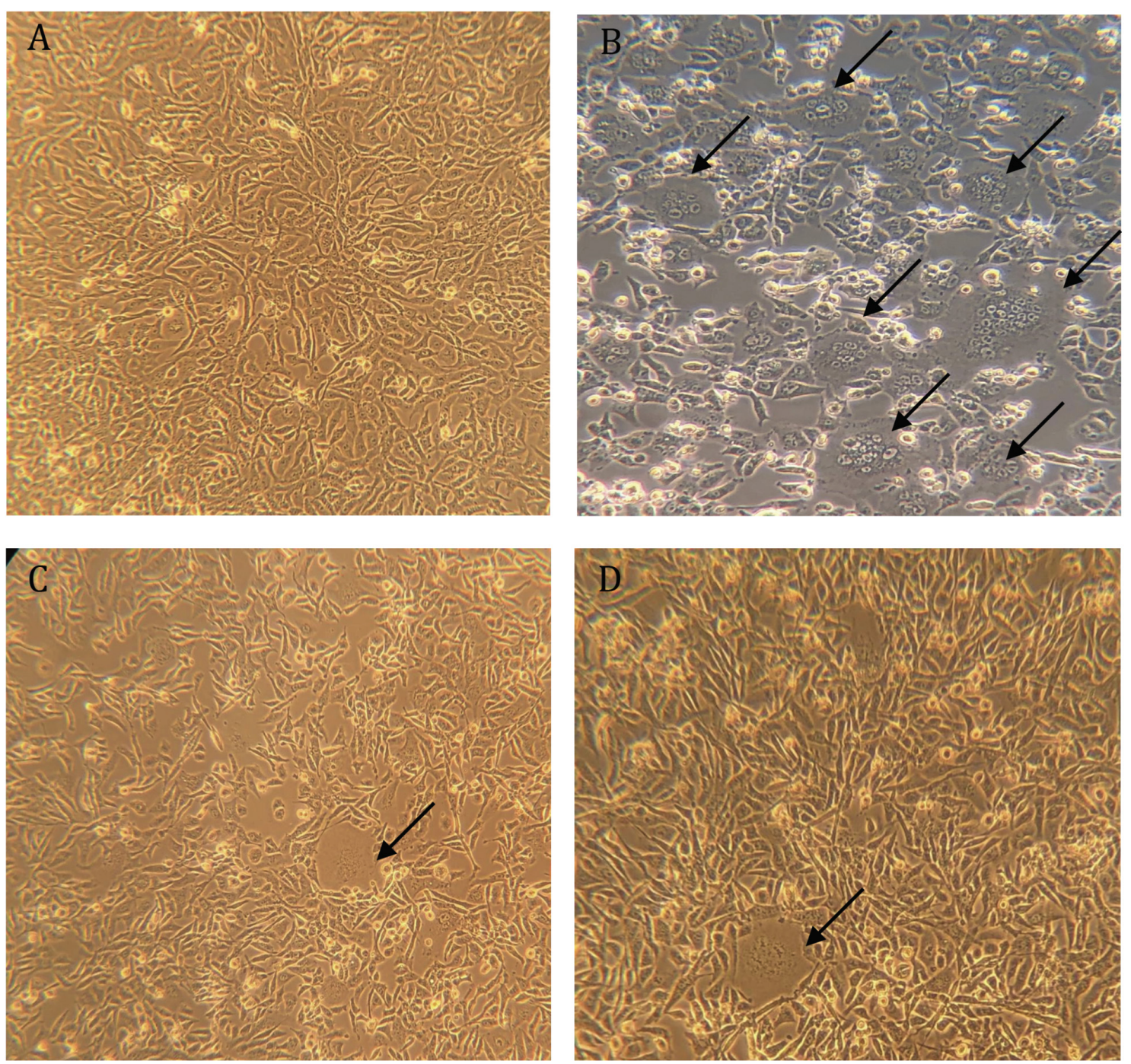

FIGURE 4 | Syncytia formation in BHK-21/WI-2 cells $24 \mathrm{~h}$ post-transfection. (A) Cell control. (B) Cells transfected with pCAGGS-G. (C) Cells transfected with pcDNA-SARS-2-S. (D) Cells transfected with pcDNA-MERS-S. Arrows highlight the observed syncytia. Images are representative from three independent experiments.

Protocol 2 (Protocol 2: Titration Assay of the Generated Vesicular Stomatitis Virus Pseudoviruses by Measuring Luciferase Activity).

\section{Day 2: Pseudovirus Neutralization Assay}

1. In a sterile U-shaped 96 -well cell culture plate, add 60 $\mu l$ of pre-warmed DMEM-5 to all wells in columns 112 in rows $B$ to $G$.

2. Add $120 \mu$ l of pre-warmed DMEM-5 to wells $\mathrm{H} 1$ to $\mathrm{H} 6$ to serve as negative cell control; CC.

3. Add $60 \mu$ l of pre-warmed DMEM-5 to wells $\mathrm{H} 7$ to $\mathrm{H} 12$ to be used as virus control (VC).

4. Add $120 \mu \mathrm{l}$ of $1: 10$ dilution of heat-inactivated serum samples, at $56^{\circ} \mathrm{C}$ for $30 \mathrm{~min}$, in wells in row $\mathrm{A}$; add each sample in duplicate.
5. Remove $60 \mu \mathrm{l}$ from serum-containing wells in wells A1-A12, and perform 1:2 serial dilutions downward to all wells below. Other dilutions such as $1: 3$ or $0.5 \log$ could be used.

6. During each dilution step, mix well by pipetting eight times up and down.

7. Continue the dilution until row $\mathrm{G}$, and discard the final 60 $\mu l$ from the last wells in row $G$.

8. Prepare rVSV pseudovirus suspension at a concentration of $1 \times 10^{6} \mathrm{RLU}$ per ml. A total of $7.5 \mathrm{ml}$ is needed for one 96 -well plate.

9. Add $60 \mu \mathrm{l}$ of pseudovirus suspension into each well in the plate except wells $\mathrm{H} 1$ to H6 (CC).

10. Incubate the plate for $1 \mathrm{~h}$ at $37^{\circ} \mathrm{C}$ in $5 \% \quad \mathrm{CO}_{2}$ humidified incubator. 

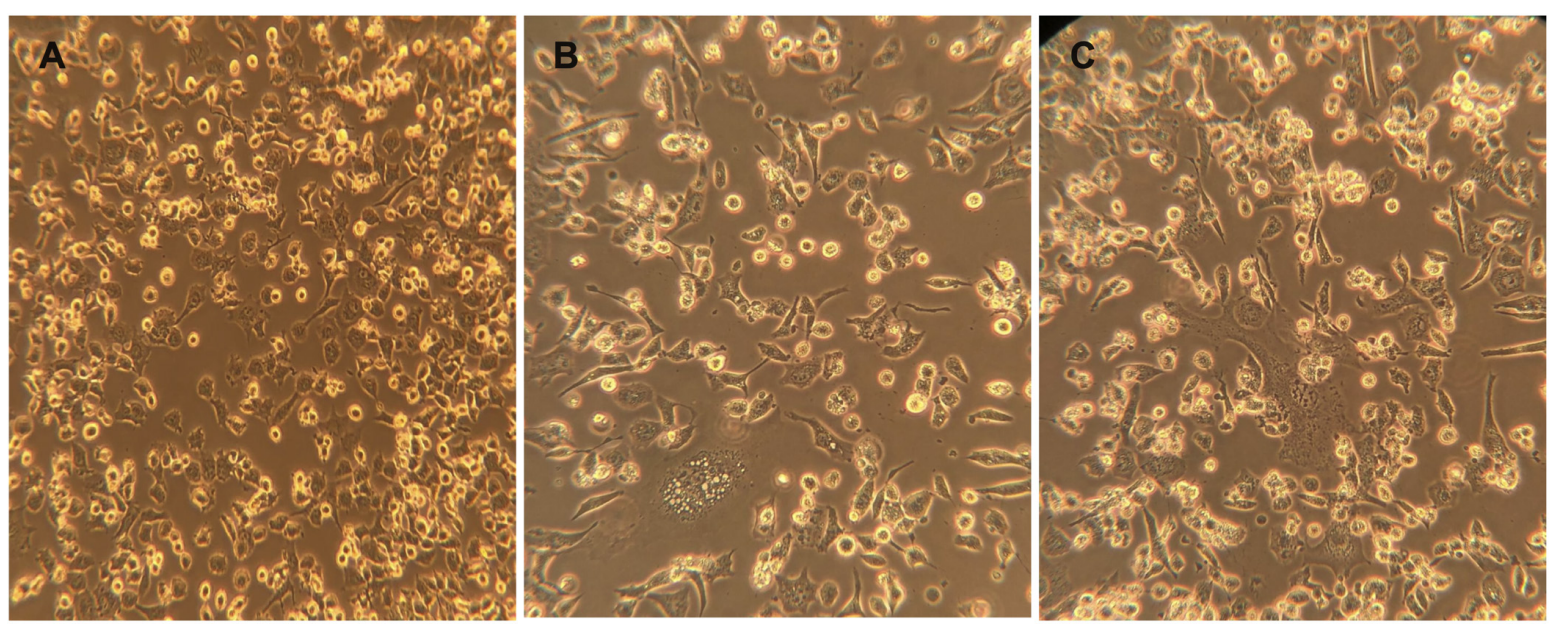

FIGURE 5 | Cells rounding $24 \mathrm{~h}$ after infection with rVSV- $\Delta \mathrm{G} / \mathrm{G}^{*}$-luciferase pseudovirus. Cytopathic effect (cells rounding) of BHK-21/WI-2 cells transfected with (A) pCAGGS-G, (B) pcDNA-SARS-2-S, or (C) pcDNA-MERS-S and infected with rVSV- $\Delta G / G^{*}$-luciferase pseudovirus. Images are representative from three independent experiments. rVSV, recombinant vesicular stomatitis virus.
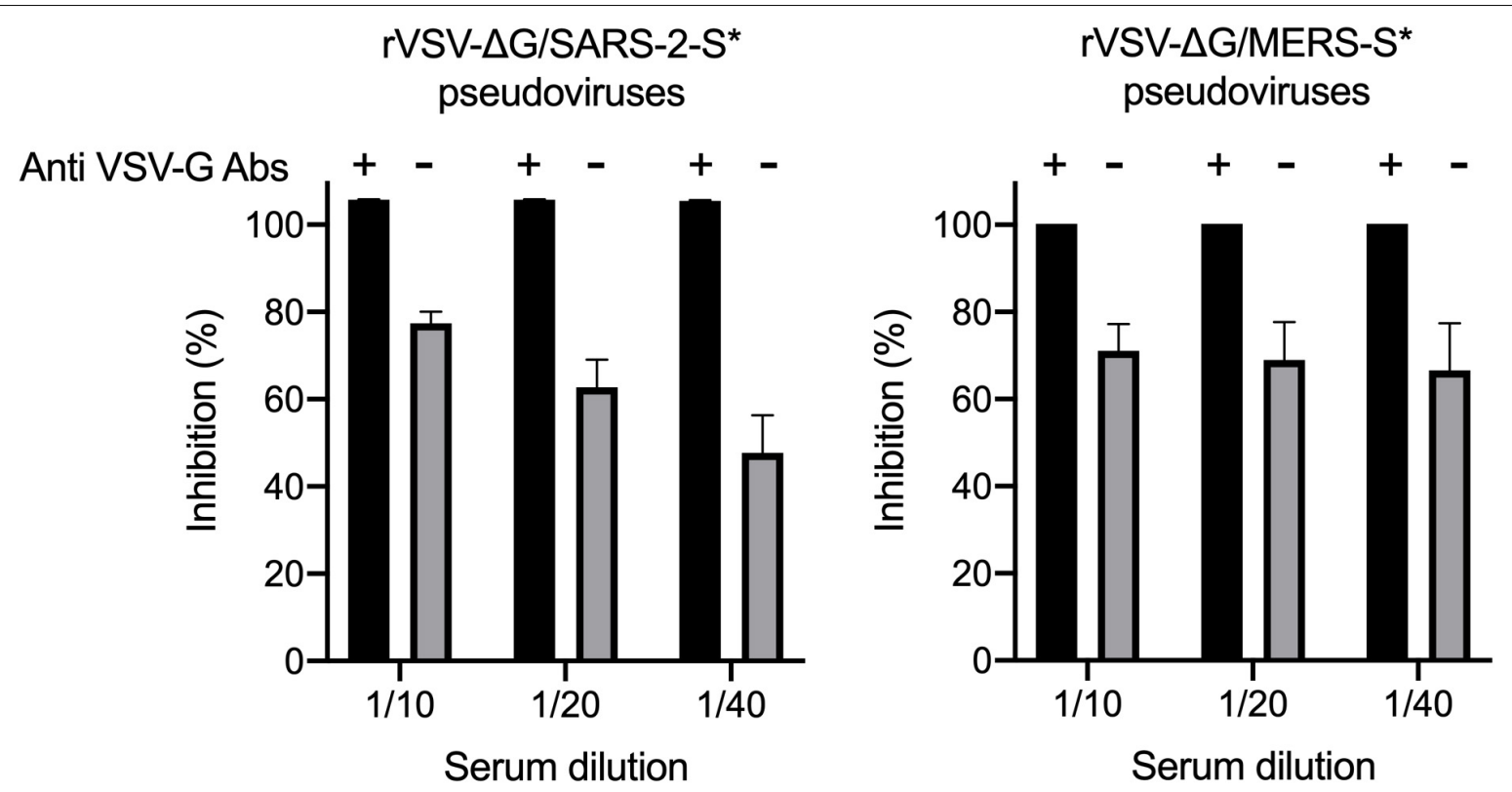

FIGURE 6 | Neutralization of rVSV pseudovirus generated in the absence or presence of anti-VSV-G polyclonal antibodies. Both rVSV- $\Delta$ G/MERS-S*-luciferase and rVSV- $\Delta$ G/SARS-2-S*-luciferase were generated in the absence or presence of anti-VSV-G polyclonal antibodies and used in neutralization assay using seropositive serum samples in Vero E6 cells. Using anti-VSV-G polyclonal antibodies always resulted in pseudoviruses without residual rVSV- $\Delta G / G^{*}-$ luciferase as shown by the complete inhibition of the luciferase activity compared with the partial inhibition when pseudoviruses were generated in absence of anti-VSV-G polyclonal antibodies, which indicated activities from residual $r V S V-\Delta G / G^{*}$-luciferase. Samples were run in duplicates, and data are shown as mean \pm SD from one representative experiment out of three independent experiments. Inhibition (\%) was calculated as 100 - [(mean RLU from each sample (virus + diluted serum) - mean RLU from $\mathrm{CC}$ /(mean RLU from VC - mean RLU from CC) × 100]. rVSV, recombinant vesicular stomatitis virus; RLU, relative luminescence unit; CC, cell-only control.

11. Take out the plated Vero E6 cells in 96-well cell culture plate from the incubator that was seeded on Day 1 , and remove the growth medium.

12. With the use of a multichannel pipette and filtered tips, transfer $100 \mu \mathrm{l}$ from all wells in the U-shaped 96-well cell culture plate to corresponding wells in the 96-well plate of Vero E6 cells.
13. Incubate the plate for $24 \mathrm{~h}$ at $37^{\circ} \mathrm{C}$ in $5 \% \mathrm{CO}_{2}$ humidified incubator.

\section{Day 3: Luciferase Assay}

1. Follow steps $1-7$, which have been described in the luciferase assay on Day 3 in Protocol 2 (Protocol 2: Titration Assay of the Generated Vesicular Stomatitis Virus 

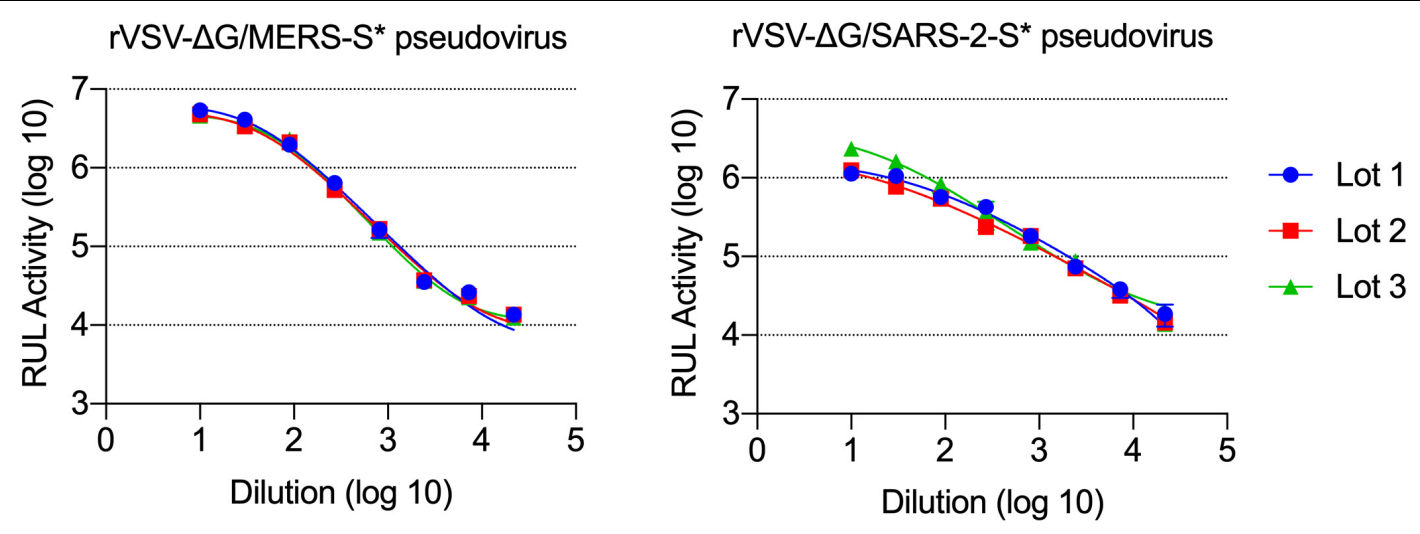

FIGURE 7 | Titration of rVSV- $\Delta$ G/MERS-S*-luciferase and rVSV- $\Delta$ G/SARS-2-S*-luciferase pseudoviruses. Generated viruses were serially diluted in a 0.5 log dilution and used to titrate luciferase activity in Vero E6 cells. Luciferase activity was plotted against each dilution using 4PL logistic curve. Samples were run in duplicates, and data are shown as mean \pm SD. Data are shown from three different production lots of rVSV- $\Delta G / M E R S-S^{*}$-luciferase and rVSV- $\Delta G / S A R S-2-S^{*}$-luciferase pseudoviruses. rVSV, recombinant vesicular stomatitis virus.

Pseudoviruses by Measuring Luciferase Activity) to measure luciferase activity.

2. Inhibition (\%) of luciferase activity from each serum dilution could be calculated as follows: 100 - [(mean RLU from each sample (virus + serum) - mean RLU from CC)/(mean RLU from VC - mean RLU from CC) $\times 100]$.

3. Inhibition (\%) should be plotted against each dilution using four-parameter logistic (4PL) curve, and 50\% inhibitory concentration $\left(\mathrm{IC}_{50}\right)$ values for each sample could be computed using graph prism or similar software.

\section{RESULTS}

\section{Generation of rVSV- $\Delta$ G/MERS-S*-Luciferase and rVSV- $\Delta$ G/SARS-2-S*-Luciferase Pseudoviruses}

The highly transfectable BHK-21/WI-2 cell line was selected to recover the rVSV pseudoviruses. BHK-21/WI-2 cells were initially transfected with pcDNA mammalian expression vector expressing the $\mathrm{S}$ protein of either MERS-CoV or SARS-CoV2. We used pcDNA expressing MERS-CoV $S$ to generate rVSV pseudovirus bearing MERS-CoV S (rVSV- $\triangle$ G/MERS$S^{*}$-luciferase), and pcDNA expressing SARS-CoV-2 $S$ is used to generate rVSV pseudovirus bearing SARS-CoV-2 S (rVSV$\Delta$ G/SARS-2-S*-luciferase). By examining the transfected cells $24 \mathrm{~h}$ post-transfection using inverted microscope, syncytia were found throughout the cell monolayer. They were more obvious in cells transfected with pCAGGS-G, which means that sufficient VSV-G protein has been expressed (Figure 4).

Different mammalian expression vectors such as pCAGGS, plasmid purification kits, or methods, or transfection reagents could be used (Grehan et al., 2015; Almasaud et al., 2020). Additionally, this system could be used to generate any pseudotyped viruses expressing the protein of interest simply by using other plasmids. It is recommended to generate additional working stocks of rVSV- $\Delta \mathrm{G} / \mathrm{G}^{*}$-luciferase virus by amplifying an aliquot of the rVSV- $\Delta \mathrm{G} / \mathrm{G}^{*}$-luciferase stock from Kerafast using BHK-21/WI-2 cells transfected with pCAGGS-G (expression plasmid encoding VSV-G protein) as described in step 3 on Day 2 in Protocol 1 (Protocol 1: Production of Vesicular Stomatitis Virus Pseudoviruses Bearing Coronavirus S Protein). Plaque assay can be used to determine $\mathrm{rVSV}-\Delta \mathrm{G} / \mathrm{G}^{*}$-luciferase titer, and calculate MOI needed for step 1 on Day 3 in Protocol 1 (Protocol 1: Production of Vesicular Stomatitis Virus Pseudoviruses Bearing Coronavirus S Protein) as previously described (Whitt, 2010).

The transfected BHK-21/WI-2 cells with pcDNA/MERS-S, pcDNA/SARS-2-S, and pCAGGS-G were infected with rVSV$\Delta \mathrm{G} / \mathrm{G}^{*}$-luciferase stock after $24 \mathrm{~h}$ of the transfection. The pseudoviruses rVSV- $\triangle$ G/MERS-S*-luciferase, rVSV- $\Delta$ G/SARS2 -S*-luciferase, and the PC $\operatorname{rVSV}-\Delta \mathrm{G} / \mathrm{G}^{*}$-luciferase were collected from the supernatants $24 \mathrm{~h}$ post-infection. Infecting the cells with rVSV- $\Delta \mathrm{G} / \mathrm{G}^{*}$-luciferase pseudovirus caused cell rounding, which was observed in all transfected BHK-21/WI-2 cells after $24 \mathrm{~h}$ (Figure 5).

One of the most common problems that could occur during the generation of pseudoviruses is having residual or background rVSV- $\Delta \mathrm{G} / \mathrm{G}^{*}$-luciferase pseudovirus in the collected supernatants (Nie et al., 2020). Complete removal of excess rVSV- $\Delta \mathrm{G} / \mathrm{G}^{*}$-luciferase that do not infect the cells was done by washing the cell monolayer twice with $1 \times$ PBS as well as using DMEM-5 supplemented with anti-VSV-G antibodies. As shown in Figure 6, complete inhibition of the luciferase activity by seropositive serum samples was observed in all pseudoviruses (rVSV- $\triangle \mathrm{G} / \mathrm{MERS}-\mathrm{S}^{*}$-luciferase and rVSV$\Delta$ G/SARS-2-S*-luciferase) generated in presence of anti-VSV-G polyclonal antibodies as compared with the partial inhibition of pseudoviruses that were generated in the absence antiVSV-G polyclonal antibodies. While we used 1:1,000 dilution of anti-VSV-G polyclonal antibodies and found it effective in inhibiting residual $\mathrm{rVSV}-\Delta \mathrm{G} / \mathrm{G}^{*}$-luciferase viruses, dilution of in-house produced anti-VSV-G polyclonal antibodies is dependent on the antibody titer and should be optimized. 

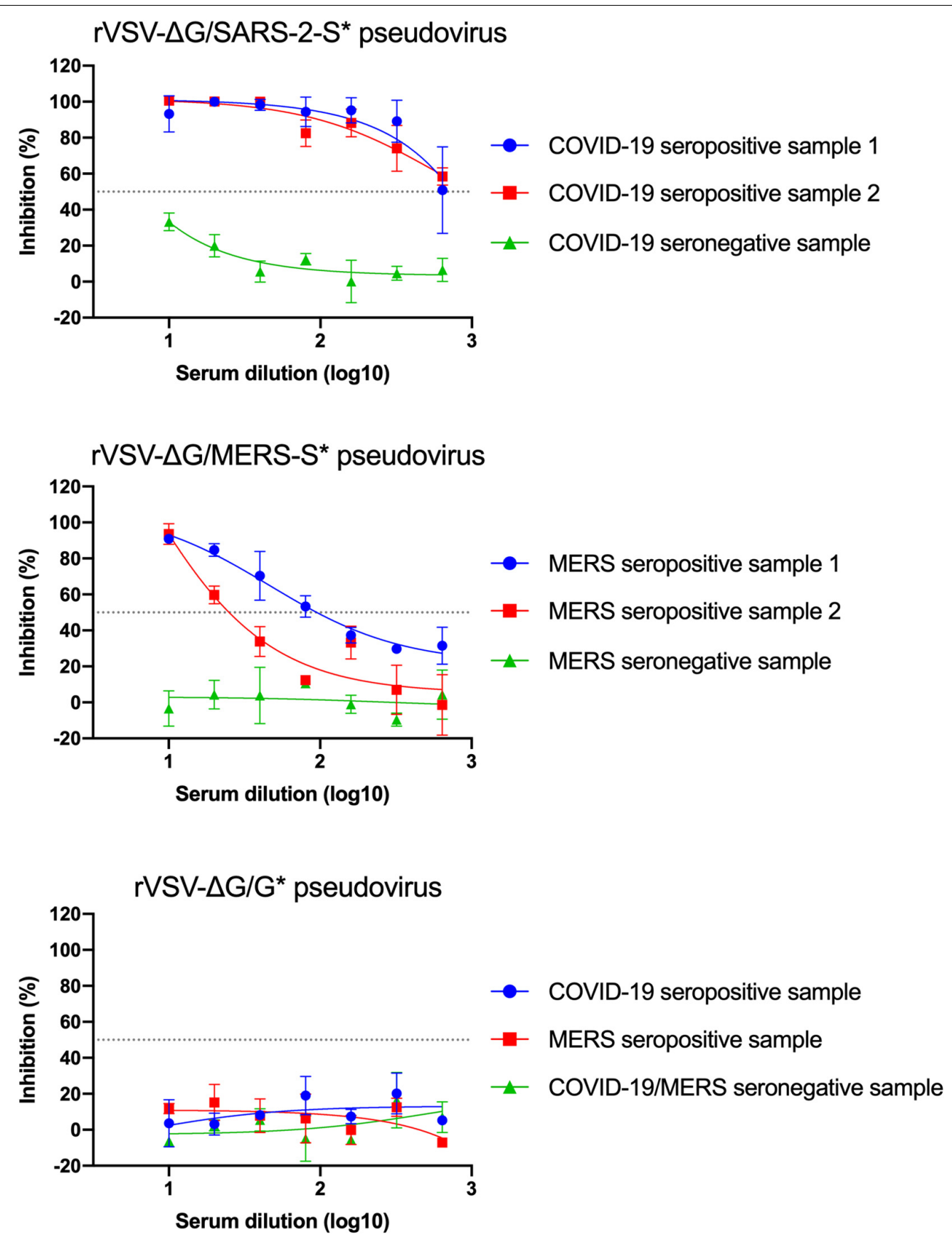

FIGURE 8 | Example of neutralization activity using the generated pseudoviruses. Inhibition of rVSV- $\Delta$ G/MERS-S*-luciferase, rVSV- $\Delta G / S A R S-2-S^{*}$-luciferase, or rVSV- $\Delta G / G^{*}$-luciferase pseudoviruses using seropositive and seronegative human serum samples in Vero E6 cells. Data were plotted using 4PL logistic curves as indicated in section "Materials and Methods." Serum samples were diluted starting from 1:10 to 1:640. Samples were run in duplicates, and data are shown as mean \pm SD from one representative experiment out of three independent experiments. rVSV, recombinant vesicular stomatitis virus.

\section{Titration of the Generated}

\section{rVSV- $\Delta G$ /MERS-S*-Luciferase and rVSV- $\Delta$ G/SARS-2-S*-Luciferase}

\section{Pseudoviruses}

Measuring titers of the produced pseudoviruses was based on luminescence signal reads obtained from the activity of the expressed luciferase. Vero E6 cells were selected for pseudovirus titration as they are permissive for MERS-CoV, SARS-CoV-2, and VSV. After $24 \mathrm{~h}$ of infecting the seeded Vero E6 cells in 96-well white or black plate with clear bottom with serial dilution of generated pseudoviruses, the cells were lysed and the luciferase activities were measured. The measured luciferase activity is defined as RLU. Based 
on the RLU values observed at each serial dilution, virus dilution vs. RLU readout was plotted to select the needed amount of virus for further experiments (Figure 7). The right titer of the generated pseudoviruses was selected as the dilution that results in an RLU above cell-only control and in the linear part of the curve $\left(1 \times 10^{4}-5 \times 10^{5}\right)$. In our case, we used $\sim 5 \times 10^{4}$ RLU/well to maximize the use of each lot of the produced pseudoviruses, and it worked very well in neutralization assays. Figure 7 also shows the activity from different lots of each produced pseudovirus (rVSV- $\Delta \mathrm{G} / \mathrm{MERS}-\mathrm{S}^{*}$-luciferase and rVSV- $\Delta$ G/SARS-2-S*-luciferase pseudoviruses), which shows minimum variation between the different lots.

\section{Neutralization Assay With rVSV- $\Delta G$ /MERS-S*-Luciferase and rVSV- $\Delta$ G/SARS-2-S*-Luciferase Pseudoviruses}

Determination of $\mathrm{nAb}$ titers in serum samples depends on measuring the inhibition level of luciferase activity from pseudoviruses in cells, which is correlated with the inhibition of virus entry into Vero E6 cells. Twofold serial dilutions of seropositive serum samples from confirmed MERS-CoV and SARS-CoV-2 infected patients were prepared and pre-incubated with $5 \times 10^{4}$ RLU of rVSV- $\triangle$ G/MERS-S*-luciferase and rVSV$\Delta$ G/SARS-2-S*-luciferase pseudoviruses, respectively. Sera from healthy donor were included as a negative control. As shown in Figure 8, dose-dependent inhibition in luciferase activity was observed with tested seropositive serum samples, in contrast to the seronegative control sera, which did not show any significant changes in the luciferase activity at any dilution. These results demonstrated the both generated pseudoviruses specially neutralized by corresponding seropositive serum samples. As expected, testing these serum samples against rVSV$\Delta \mathrm{G} / \mathrm{G}^{*}$-luciferase pseudovirus showed no inhibition (Figure 8). Neutralizing $\mathrm{Ab}$ titer could be computed as $\mathrm{IC}_{50}$ using $4 \mathrm{PL}$ logistic curve in graph prism or similar software. Otherwise, relative $50 \% \mathrm{nAb}$ titers $\left(\mathrm{NT}_{50}\right)$ in seropositive serum samples could be determined as the reciprocal of the highest serum dilution that reduces luciferase activity by $50 \%$ relative to $\mathrm{VC}$ only.

\section{DISCUSSION}

We have used the rVSV- $\Delta \mathrm{G} / \mathrm{G}^{*}$-luciferase system to measure nAbs against MERS-CoV and SARS-CoV-2 in serum samples. The detailed protocols described here include all the steps are needed to generate rVSV pseudoviruses to implement neutralization assay for highly pathogenic CoVs in BSL-2 laboratories. The availability of such protocol would help different laboratories and researchers to study the seroprevalence

\section{REFERENCES}

Al-Amri, S. S., Abbas, A. T., Siddiq, L. A., Alghamdi, A., Sanki, M. A., Al-Muhanna, M. K., et al. (2017). Immunogenicity of candidate MERS-CoV DNA vaccines based on the spike protein. Sci. Rep. 7:44875. doi: 10.1038/srep44875 of CoVs in the population, to study immune response in infected individuals, and to evaluate vaccine immunogenicity and viral entry inhibitors (Fukushi et al., 2005; Lester et al., 2019; Almasaud et al., 2020; Nie et al., 2020). By following our protocol, generation and titration of desired pseudoviruses can be performed easily and quickly using basic techniques and equipment in BSL2 environment. Pseudovirus neutralization assay takes 3 days, and up to six serum samples could be tested per plate. In our work, we succeed to generate pseudovirus stocks without having them contaminated with residual $r V S V-\Delta G / G^{*}$-luciferase viruses that did not infect cells. We found that adding anti-VSV-G antibodies has improved the neutralization assay by eliminating high background readings of luciferase activity that could lead to false-negative results. While we used full-length $S$ gene from SARS-CoV-2 to generate good titers of rVSV- $\Delta$ G/SARS-2-S*luciferase to perform the neuralization assays, it has recently been reported that deletion of 21 amino acid at the cytoplasmic tail of the S protein from SARS-CoV-2 could enhance the titer significantly (Case et al., 2020). The work presented here is reproducible and allows testing human or animal sera without using live viruses in BSL-3 bio-containment laboratories.

\section{DATA AVAILABILITY STATEMENT}

All datasets generated for this study are included in the article/supplementary material.

\section{AUTHOR CONTRIBUTIONS}

SA, AA, M-ZE, and AH performed the methodology and testing. SA, AA, MA, and AH wrote the original draft. SA, $\mathrm{AA}, \mathrm{MA}, \mathrm{M}-\mathrm{ZE}$, and $\mathrm{AH}$ wrote, reviewed, and edited the manuscript. All authors contributed to the article and approved the submitted version.

\section{FUNDING}

This work was supported by King Abdulaziz City for Science and Technology (KACST) through research grant program (number 09-1), which is a part of the Targeted Research Program.

\section{ACKNOWLEDGMENTS}

We would like to thank the King Fahd Medical Research Center and the King Abdulaziz University (KAU) for their continuous support. We gratefully acknowledge Kerafast for providing materials to conduct the work. The illustrations were created by BioRender.com.

Algaissi, A., and Hashem, A. M. (2020). Evaluation of MERS-CoV neutralizing antibodies in sera using live virus microneutralization assay. Methods Mol. Biol. 2099, 107-116. doi: 10.1007/978-1-0716-0211-9_9

Almasaud, A., Alharbi, N. K., and Hashem, A. M. (2020). Generation of MERS$\mathrm{CoV}$ pseudotyped viral particles for the evaluation of neutralizing antibodies in 
mammalian sera. Methods Mol. Biol. 2099, 117-126. doi: 10.1007/978-1-07160211-9_10

Case, J. B., Rothlauf, P. W., Chen, R. E., Liu, Z., Zhao, H., and Kim, A. S. (2020). Neutralizing antibody and soluble ACE2 inhibition of a replication-competent VSV-SARS-CoV-2 and a clinical isolate of SARS-CoV-2. bioRxiv [Preprint]. doi: $10.1101 / 2020.05 .18 .102038$

Cui, J., Li, F., and Shi, Z. L. (2019). Origin and evolution of pathogenic coronaviruses. Nat. Rev. Microbiol. 17, 181-192. doi: 10.1038/s41579-01 8-0118-9

Degnah, A. A., Al-Amri, S. S., Hassan, A. M., Almasoud, A. S., Mousa, M., Almahboub, S. A., et al. (2020). Seroprevalence of MERS-CoV in healthy adults in western Saudi Arabia, 2011-2016. J. Infect. Public Health 13, 697-703. doi: 10.1016/j.jiph.2020.01.001

Fehr, A. R., and Perlman, S. (2015). Coronaviruses: an overview of their replication and pathogenesis. Methods Mol. Biol. 1282, 1-23. doi: 10.1007/978-1-49392438-7_1

Fukushi, S., Mizutani, T., Saijo, M., Matsuyama, S., Miyajima, N., Taguchi, F., et al. (2005). Vesicular stomatitis virus pseudotyped with severe acute respiratory syndrome coronavirus spike protein. J. Gen. Virol. 86, 2269-2274. doi: 10.1099/ vir.0.80955-0

Grehan, K., Ferrara, F., and Temperton, N. (2015). An optimised method for the production of MERS-CoV spike expressing viral pseudotypes. MethodsX 2, 379-384. doi: 10.1016/j.mex.2015.09.003

Hoffmann, M., Kleine-Weber, H., Schroeder, S., Kruger, N., Herrler, T., Erichsen, S., et al. (2020). SARS-CoV-2 cell entry depends on ACE2 and TMPRSS2 and is blocked by a clinically proven protease inhibitor. Cell 181, 271.e8-280.e8. doi: 10.1016/j.cell.2020.02.052

Kandeel, M., Ibrahim, A., Fayez, M., and Al-Nazawi, M. (2020). From SARS and MERS-CoVs to SARS-CoV-2: moving toward more biased codon usage in viral structural and nonstructural genes. J. Med. Virol. 92, 660-666. doi: 10.1002/jmv. 25754

Ksiazek, T. G., Erdman, D., Goldsmith, C. S., Zaki, S. R., Peret, T., Emery, S., et al. (2003). A novel coronavirus associated with severe acute respiratory syndrome. N. Engl. J. Med. 348, 1953-1966. doi: 10.1056/NEJMoa030781

Lester, S., Harcourt, J., Whitt, M., Al-Abdely, H. M., Midgley, C. M., Alkhamis, A. M., et al. (2019). Middle East respiratory coronavirus (MERS-CoV) spike (S) protein vesicular stomatitis virus pseudoparticle neutralization assays offer a reliable alternative to the conventional neutralization assay in human seroepidemiological studies. Access Microbiol. 1. doi: 10.1099/ acmi.0.000057

Liu, R., Wang, J., Shao, Y., Wang, X., Zhang, H., Shuai, L., et al. (2018). A recombinant VSV-vectored MERS-CoV vaccine induces neutralizing antibody and $\mathrm{T}$ cell responses in rhesus monkeys after single dose immunization. Antivir. Res. 150, 30-38. doi: 10.1016/j.antiviral.2017.12.007
Ma, C., Su, S., Wang, J., Wei, L., Du, L., and Jiang, S. (2020). From SARS-CoV to SARS-CoV-2: safety and broad-spectrum are important for coronavirus vaccine development. Microbes Infect. 22, 245-253. doi: 10.1016/j.micinf.2020.05.004

Nie, J., Li, Q., Wu, J., Zhao, C., Hao, H., Liu, H., et al. (2020). Establishment and validation of a pseudovirus neutralization assay for SARS-CoV-2. Emerg. Microbes Infect. 9, 680-686. doi: 10.1080/22221751.2020.1743767

Padron-Regalado, E. (2020). Vaccines for SARS-CoV-2: lessons from other coronavirus strains. Infect. Dis. Ther. 9, 255-274. doi: 10.1007/s40121-02000300- $\mathrm{x}$

Rodriguez, L. (2002). L. Emergence and re-emergence of vesicular stomatitis in the United States. Virus Res. 85, 211-219. doi: 10.1016/s0168-1702(02)00026-6

Ruedas, J. B., and Connor, J. H. (2017). Generating recombinant vesicular stomatitis viruses for use as vaccine platforms. Methods Mol. Biol. 1581, 203222. doi: 10.1007/978-1-4939-6869-5_12

Tani, H., Morikawa, S., and Matsuura, Y. (2011). Development and applications of VSV vectors based on cell tropism. Front. Microbiol. 2:272. doi: 10.3389/fmicb. 2011.00272

Tse, L. V., Meganck, R. M., Graham, R. L., and Baric, R. S. (2020). The current and future state of vaccines, antivirals and gene therapies against emerging coronaviruses. Front. Microbiol. 11:658. doi: 10.3389/fmicb.2020.00658

Whitt, M. A. (2010). Generation of VSV pseudotypes using recombinant $\Delta G$ VSV for studies on virus entry, identification of entry inhibitors, and immune responses to vaccines. J. Virol. Methods 169, 365-374. doi: 10.1016/j.jviromet. 2010.08.006

Wu, D., Wu, T., Liu, Q., and Yang, Z. (2020). The SARS-CoV-2 outbreak: what we know. Int. J. Infect. Dis. 94, 44-48. doi: 10.1016/j.ijid.2020.03.004

Zaki, A. M., van Boheemen, S., Bestebroer, T. M., Osterhaus, A. D., and Fouchier, R. A. (2012). Isolation of a novel coronavirus from a man with pneumonia in Saudi Arabia. N. Engl. J. Med. 367, 1814-1820. doi: 10.1056/NEJMoa1211721

Zhu, N., Zhang, D., Wang, W., Li, X., Yang, B., Song, J., et al. (2020). A novel coronavirus from patients with pneumonia in China, 2019. N. Engl. J. Med. 382, 727-733. doi: 10.1056/NEJMoa2001017

Conflict of Interest: The authors declare that the research was conducted in the absence of any commercial or financial relationships that could be construed as a potential conflict of interest.

Copyright (c) 2020 Almahboub, Algaissi, Alfaleh, ElAssouli and Hashem. This is an open-access article distributed under the terms of the Creative Commons Attribution License (CC BY). The use, distribution or reproduction in other forums is permitted, provided the original author(s) and the copyright owner(s) are credited and that the original publication in this journal is cited, in accordance with accepted academic practice. No use, distribution or reproduction is permitted which does not comply with these terms. 